\title{
Annie Brudo, Le Langage en représentation. Essai sur le théâtre de Balzac
}

\section{Marco Stupazzoni}

\section{Q OpenEdition}

1 Journals

\section{Edizione digitale}

URL: http://journals.openedition.org/studifrancesi/8965

DOI: $10.4000 /$ studifrancesi.8965

ISSN: 2421-5856

\section{Editore}

Rosenberg \& Sellier

\section{Edizione cartacea}

Data di pubblicazione: 1 octobre 2008

Paginazione: 471-472

ISSN: 0039-2944

\section{Notizia bibliografica digitale}

Marco Stupazzoni, «Annie Brudo, Le Langage en représentation. Essai sur le théâtre de Balzac», Studi Francesi [Online], 155 (LII | II) | 2008, online dal 30 novembre 2015, consultato il 12 janvier 2021. URL: http://journals.openedition.org/studifrancesi/8965 ; DOI: https://doi.org/10.4000/studifrancesi.8965

Questo documento è stato generato automaticamente il 12 janvier 2021.

\section{(c) (i) (9)}

Studi Francesi è distribuita con Licenza Creative Commons Attribuzione - Non commerciale - Non opere derivate 4.0 Internazionale. 


\title{
Annie Brudo, Le Langage en représentation. Essai sur le théâtre de Balzac
}

\author{
Marco Stupazzoni
}

\section{NOTIZIA}

ANNIE BRUDO, Le Langage en représentation. Essai sur le théâtre de Balzac, Fasano-Paris, Schena-Presses de l'Université de Paris-Sorbonne, «Biblioteca della ricerca», 2004, pp. 282.

1 Questo organico e interessante volume di Annie Brudo è interamente dedicato allo studio attento della ricca produzione teatrale di Balzac; in esso, sono considerati e analizzati con precisione e con un costante e puntuale riferimento ai testi, la natura, $\mathrm{i}$ meccanismi, i procedimenti, le tecniche verbali e non verbali inerenti al teatro balzachiano (tragedie, commedie, melodrammi) e alla sua particolare specificità. Il corpus dei testi studiati dall'autore comprende soltanto l'insieme delle cosiddette “oeuvres achevées" (da Le Nègre del 1822 a Le Faiseur del 1848) con l'esclusione di Cromwell.

2 L'opera di A. Brudo si articola in due momenti fondamentali: nella prima sezione, «L'Univers de la représentation», l'autore indaga sulla complessa nozione di situazione teatrale e, più particolarmente, sulle differenti accezioni a cui questa nozione può riferirsi e applicarsi. Anzitutto, la situazione espositiva iniziale (prologo e primo atto) dove le informazioni «utiles à l'établissement de la situation sont généralement claires et exhaustives» e assumono la funzione di «véritables indices» (p.31). La situazione drammatica, ossia gli elementi che formano l'intreccio favoriscono la progressione dell'azione e alimentano la tensione drammatica dell'opera: generalmente, scrive A. Brudo, si tratta di un'azione «riche en péripéties et en coûps de théâtre, aux antipodes de la rigueur et de la simplicité de la tragédie classique» (p. 40), che, però, in 
molti casi, si rivela eccessivamente ridondante "par excès de données de matière» (p. 54). Di particolare interesse, è l'esame della "situation d'énonciation", vale a dire del contesto di comunicazione (spazio e tempo) entro cui agiscono i personaggi. Le figure (soprattutto maschili) del teatro balzachiano, il cui fascino e le cui azioni spesso eclatanti si inscrivono in una dimensione di «action excessive» (p. 63), presentano non poche affinità con i loro omologhi romanzeschi. Per quel che riguarda la funzione del tempo nel teatro di Balzac, A. Brudo osserva giustamente che lo scrittore, "peu sensibile à la révolution opérée par le drame romantique», resta quasi sempre fedele alle regole dell'unità di tempo: egli infatti «recourt peu au drame historique préférant de beaucoup illustrer les moeurs de la société contemporaine»(p.91). Quanto all'impiego diffuso del tempo dietetico, l'autore ritiene che esso rappresenta «l'indice du lien qui le rattache aux procédés de l'écriture narrative», anche se si rivela, a suo giudizio, come uno dei «points faibles de la production théâtrale» (ibid.) balzachiana. Visto in stretta correlazione con il tempo, lo spazio (mimetico) dà corpo, nel teatro di Balzac, all'azione confermando ancora una volta quel «sens inné de la théâtralité» che è proprio dello scrittore. Balzac, puntualizza A. Brudo, «a le sens du spectacle, de la scène à effet» e "la précision avec laquelle sont indiqués les gestes et les attitudes des personnages en sont une preuve ultérieure»(p.116). Non meno significativa è la "situation finale" sempre rigorosamente inscritta da Balzac nell'azione e dove lo scrittore mostra le sue qualità di autore drammatico nel mantenere vivi l'interesse e la curiosità del lettore-spettatore.

3 Nella seconda parte del volume, «La Représentation du langage», A. Brudo considera più da vicino gli elementi costitutivi della rappresentazione teatrale di Balzac con un riferimento particolare ai procedimenti stilistici proprî del discorso drammatico balzachiano. Lo scrittore cura particolarmente la qualità e l'efficacia degli scambi dialogici: la sua abilità dialettica lo conduce «sans effort à trouver le juste équilibre entre la variété des tons et l'unité de style» (p. 180). L'azione trova quindi la sua più efficace esplicitazione di senso nella parola e la sua realizzazione più compiuta nel dialogo in un costante equilibrio, volutamente ricercato da Balzac, tra tradizione e modernità. Da questo punto di vista, l'impiego frequente e disinvolto di procedimenti tradizionali quali i monologhi, le "tirades" e gli "apartés" trovano a volte «une utilisation originale, indice d'un renouvellement de la matière dramatique», soprattutto quando sono «les personnages secondaires qui les exploitent» (p. 270). A questo si aggiunga che l'abbondante utilizzo di varie tipologie didascaliche rappresenta una ulteriore conferma della dedizione con cui Balzac redigeva le sue "pièces" in vista della loro rappresentazione.

4 Nel ribadire la positività e il rilievo dell'esperienza teatrale balzachiana, A. Brudo riflette, in conclusione, sui rapporti che legarono il Théâtre di Balzac alla sua produzione romanzesca: «dans le théâtre - sottolinea bene l'autore - Balzac ne voyait pas d'ailleurs une simple transposition de ses romans mais bien plutôt l'exploitation d'autres thèmes qui lui tenaient à coeur et qu'une représentation scénique aurait pu rendre plus efficaces» (p. 271). 